\title{
ALTERNATIVE CRITERIA FOR THE BOUNDEDNESS OF VOLTERRA INTEGRAL OPERATORS IN LEBESGUE SPACES
}

\author{
Vladimir D. StePANOV AND ElEnA P. USHAKOVA
}

\begin{abstract}
Three different criteria for $L_{p}-L_{q}$ boundedness of Volterra integral operator (??) with locally integrable weight functions $w, v$ and a non-negative kernel $k(x, y)$ satisfying Oinarov's condition for each case $1<p \leqslant q<\infty$ and $1<q<p<\infty$ are given. Relations between components of the boundedness constants are described.
\end{abstract}

Mathematics subject classification (2000): Primary 26D10; Secondary 47B38.

Keywords and phrases: Integral operators, Lebesgue spaces, weights, boundedness.

\section{REFERENCES}

[1] S. Bloom And R. Kerman, Weighted norm inequalities for operators of Hardy type, Proc. Amer. Math. Soc., 113 (1991), 135-141.

[2] D. E. Edmunds AND W. D. Evans, Hardy Operators, Function Spaces and Embeddings, SpringerVerlag, Berlin, 2004. $326 \mathrm{p}$.

[3] D. E. Edmunds And V. D. Stepanov, On the singular numbers of certain Volterra integral operators, J. Funct. Anal., 134 (1995), 222-246.

[4] I. M. Glazman, Direct methods of qualitative spectral analysis of singular differential operators, Translated from the Russian by the IPST staff Izrael Program for Scientific Translations, Jerusalem, 1965; Daniel Davey \& Co., Inc., New York 1966 ix+234 pp.

[5] M. L. Goldman, H. P. Heinig and V. D. Stepanov, On the principle of duality in Lorents spaces, Can. J Math., 48 (1996), 959-979.

[6] G. H. Hardy, J. E. LitTlewood and G. Pólya, Inequalities, Cambridge University Press, 1934.

[7] L. V. Kantorovich and G. P. Akilov, Functional Analysis, Pergamon Press, Oxford, 1982.

[8] A. Kufner And L. E. Persson, Weighted inequalities of Hardy type, World Scientific Publishing Co, Singapore/New Jersey/London/Hong Kong, 2003.

[9] Q. LAI, Weighted modular inequalities for Hardy type operators, Proc. London Math. Soc., 79 (1999), 649-672.

[10] E. Lomakina And V. D. Stepanov, On the Hardy-type integral operators in Banach function spaces, Publ. Mat., 42 (1998), 165-194.

[11] E. LOMAKINA AND V. D. STEPANOV, Asymptotic estimates for approximative and entropy numbers of the one-weight Riemann-Liouville operator, Siberian Advances in Math, 17 (2007), 1-36.

[12] V. G. MaZYA, Sobolev Spaces, Springer-Verlag, Berlin, 1985. 415 p.

[13] R. Oinarov, Two-sided estimates of the norm of some classes of integral operators, Proc. Steklov Inst. Math., 204, 3 (1994), 205-214.

[14] L.-E. Persson AND V. D. STEPANOv, Weighted integral inequalities with the geometric mean operator, J. Ineq. Appl., 7, 5 (2002), 727-746.

[15] D. V. Prokhorov, Weighted Hardy's inequalities for negative indices, Publ. Mat., 48 (2004), 423 443.

[16] D. V. Prokhorov, Hardy inequality with three measures, Proc. Steklov Inst. Math., 255 (2006), 233-245.

[17] D. V. PROKHOROV, Inequalities of Hardy type for a class of integral operators with measures, Anal Math., 33 (2007), 199-225. 
[18] D. V. Prokhorov And V. D. Stepanov, Weighted estimates of Riemann-Liouville operators and applications, Proc. Steklov Inst. Math., 243 (2003), 289-312.

[19] G. Sinnamon AND V. D. STEPAnOV, The weighted Hardy inequality: new proofs and the case $p=1$, J. London Math. Soc., 54 (1996), 89-101.

[20] V. D. STEPANOv, Weighted norm inequalities of Hardy type for the class of integral operators, J. London Math. Soc., 50 (1994), 105-120.

[21] V. D. Stepanov, On the lower bounds for Schatten - von Neumann norms of certain Volterra integral operators, J. London Math. Soc., 61 (2000), 905-922.

[22] V. D. StePANOV AND E. P. UshaKova, Weighted estimates for the integral operators with monotone kernels on a half-axis, Siberian Math. J., 45, 6 (2004), 1124-1134. 